\section{Determining the Size Exclusion for Nanoparticles in Citrus Leaves}

\author{
Ed Etxeberria ${ }^{1}$ and Pedro Gonzalez \\ Department of Horticultural Sciences, Citrus Research and Education \\ Center, University of Florida, 700 Experiment Station Road, Lake Alfred, \\ FL 33850
}

\section{Priyanka Bhattacharya \\ University of Dayton Research Institute, 300 College Park, Dayton, OH 45469}

Parvesh Sharma
Department of Materials Science and Engineering, University of Florida,
Gainesville, Particle Science and Technology Building, FL 32611

Pu Chun Ke

ARC Center of Excellence in Convergent Bio-Nano Science and Technology, Monash University, 381 Royal Parade, Parkville, VIC 3052, Australia

Additional index words. apoplastic space, citrus phloem, dendrimer, endocytosis, sieve elements

\begin{abstract}
Implementation of nanotechnology in agriculture is intimately dependent on the capacity of nanoparticles (NPs) to move within the plant body and reach the targeted cells. Although the fibrillar nature of the plant cell wall permits the movement of molecules through its porous matrix (apoplast), the movement of particles through the aqueous apoplastic milieu has its size limitations given the tightly knitted cellulose/ hemicellulose fiber structure. In the present study, we used fluorescent NPs of different composition and sizes, and followed their movement into citrus leaves by fluorescent microscopy. Our results indicate that in citrus leaves, the size exclusion limit for NPs is of $\approx 5.4 \mathrm{~nm}$. This conclusion was based on the capacity of PAMAM dendrimers G-4 and G-5 (4.5 and $5.4 \mathrm{~nm}$, respectively) to move through the cell wall and into the phloem, but failure of similar PAMAM dendrimers G-6 $(6.7 \mathrm{~nm})$ to move through the apoplast. Dendrimer NPs $5.4 \mathrm{~nm}$ and smaller were observed to penetrate the leaf tissue, and then taken up and mobilized by the phloem elements. The current study provides evidence on the size limit for NPs use in agriculture.
\end{abstract}

Application of nanotechnology in agriculture has remained mostly a theoretical exercise (Nair et al., 2010; Prasad et al., 2014; Thul et al., 2013) primarily due to the difficulties encountered in delivering NPs to plant tissues and cells. As a prospective tool, NPs can serve as delivery vehicles for a variety of agrochemicals including nutrients (DeRosa et al., 2010), antifungals (Jo et al., 2009; Kokina et al., 2013; Lamsal et al., 2011; Panáček et al., 2009), antibacterials (Lara et al., 2011), and genes (Christou et al., 1988; Torney et al., 2007); improve general growth profile (Arora et al., 2012); and even modify the light reflective index of leaves to disorient insect predators (C. Brodersen, personal communication). However, the potential use of NPs as efficient delivery systems depends not only on their ability to adhere and cross the plant external protective layers (cuticle, bark, endodermis in roots), but also on their physical ability to move

Received for publication 11 Feb. 2016. Accepted for publication 30 Mar. 2016.

'Corresponding author. E-mail: eetxeber@uff.edu. through the cell wall matrix and reach their target cells.

Plant cells are encased by the cell wall, a framework of primarily cellulose/hemicellulose microfibrills (Cosgrove, 1997) of different thickness depending on cell type. The fibrillar nature of the cell wall permits the movement of molecules through its porous matrix (apoplast) and forms a principal venue for short-distance metabolite transport in plants. However, the movement of particles through the aqueous apoplastic milieu has its size limitations given the tightly knitted cellulose/hemicellulose fiber structure (Cosgrove and Jarvis, 2012). Studies using a variety of techniques have estimated the pore size of cell walls to be generally $\leq 10 \mathrm{~nm}$ (Albersheim et al., 2010; Carpita et al., 1979; Chesson et al., 1997; Fleischer et al., 1999; Woehlecke and Ehwald, 1995). Based on these observations, NPs larger than $\pm 10 \mathrm{~nm}$ should not be able to travel through the cell wall, rendering them unusable as delivery systems for most types of plant applications. However, a number of studies with different plant species have reported the uptake and movement of NPs of larger sizes (Adani et al., 2010; Hischemöller et al., 2009; Khodakovskaya et al., 2009; RondeauMouro et al., 2008; Tepfer and Taylor, 1981; Wang et al., 2012; Zhu et al., 2008) up to $\approx 200 \mathrm{~nm}$ (Liu et al., 2009), suggesting that NPs' ability to permeate the cell wall also depends on other properties (Dietz and Herth, 2011; Yang et al., 2013), since some of these (shape, surface charge, and agglomeration) can be altered within biological systems (Mu et al., 2009; Powers et al., 2006; Santos et al., 2010). These results are particularly important since the capacity of NPs to penetrate live plant tissues has ramifications on their utility as smart delivery systems in agriculture (Miralles et al., 2012).

The great majority of NP studies in plants have been performed with hydroponic root systems (Hischemöller et al., 2009; Kurepa et al., 2010; Wang et al., 2012; Zhu et al., 2008), cell cultures (Kokina et al., 2013; Liu et al., 2009), seedcoats (Khodakovskaya et al., 2009), protoplasts (Etxeberria et al., 2009; Serag et al., 2011), biolistic method (Martin-Ortigosa et al., 2012), or stem injections (Corredor et al., 2009; GonzálezMelendi et al., 2008); application methods that were effective but differed from field conditions. Considering that the combined surface area of aboveground plant parts far exceeds the underground area (except in xerophytes and tundra vegetation) (Dietz and Herth, 2011) and that these are vastly more accessible, foliar application of NPs on plant shoot surfaces is highly favored (Fernandez and Eichert, 2009). NPs can gain access into leaves through open stomata (Eichert et al., 2008); however, their movement inside the leaves has been insufficiently explored with a single estimate of the palisade cell wall pore size of 4.5-5.2 nm (Carpita et al., 1979). Development of techniques involving NPs for agricultural purposes necessitates a better understanding of the capacity of plants to take up NPs and their movement inside the plant. In this paper, we aim at estimating the approximate size exclusion of the cell wall in citrus leaves. We selected citrus leaves given that they are the target of extensive ongoing NP research intended at curbing the deadly disease huanglongbing (HLB or citrus greening) (Gottwald, 2010).

\section{Materials and Methods}

NP selection, preparation, and characterization. For the present study, fluorescent NPs of different sizes and compositions (Table 1) were purchased commercially or prepared in situ, and kept in the refrigerator in the dark until use. NPs were selected for their predetermined size and fluorescent properties. Green fluorescent $\mathrm{Au}-\mathrm{NPs} 1.4 \mathrm{~nm}$ in diameter (Alexa Fluor488 conjugated nanogold) were purchased from Nanoprobes, Yaphank, NY, whereas $\mathrm{CuInS} / \mathrm{ZnS}$ nanocrystals $3.6 \mathrm{~nm}$ in diameter were obtained from MKNANO, Mississauga, ON, Canada. All three generation (Gen) 
Table 1. Type, concentration, and properties of nanoparticles used to determine the size exclusion of the citrus leaf cell wall apoplastic space; all solutions were applied directly on lasered leaves and samples were taken 2 and $4 \mathrm{~h}$ after for analysis under fluorescent microscopy.

\begin{tabular}{|c|c|c|c|c|}
\hline Size (nm) & Type & Concn & $\mathrm{Ex} / \mathrm{Em}$ & Zeta potential ( $\varsigma \mathrm{p})$ \\
\hline 1.4 & $\begin{array}{l}\text { Nanogold } \\
\text { AlexaFluor-488 }\end{array}$ & $0.8 \mu \mathrm{M}$ & $490 / 525$ & $-18.1 \pm 1.0$ \\
\hline 3.6 & $\begin{array}{l}\text { CuInS/ZnS } \\
\text { Nanocrystals }\end{array}$ & $9 \mu \mathrm{M}$ & $430 / 530$ & $-29.2 \pm 3.2$ \\
\hline 4.5 & $\begin{array}{l}\text { PAMAM dendrimers } \\
\text { Fourth generation-Alexa Fluor }\end{array}$ & $197 \mu \mathrm{M}$ & $490 / 525$ & $+30.7 \pm 2.9$ \\
\hline 5.4 & $\begin{array}{l}\text { PAMAM dendrimers } \\
\text { Fifth generation-FITC }\end{array}$ & $430 \mu \mathrm{M}$ & $490 / 525$ & $+23.2 \pm 1.5$ \\
\hline 6.7 & $\begin{array}{l}\text { PAMAM dendrimers } \\
\text { Sixth generation-FITC }\end{array}$ & $286 \mu \mathrm{M}$ & $490 / 525$ & $+5.35 \pm 3.1$ \\
\hline 10 & $\mathrm{CdSeS} / \mathrm{ZnS}$ & $10 \mathrm{~nm}$ & $430 / 530$ & $-28 \pm 8.1$ \\
\hline 15 & $\mathrm{CdSeS} / \mathrm{ZnS}$ & $2 \mu \mathrm{M}$ & $405 / 565$ & $-3.6 \pm 1.9$ \\
\hline
\end{tabular}

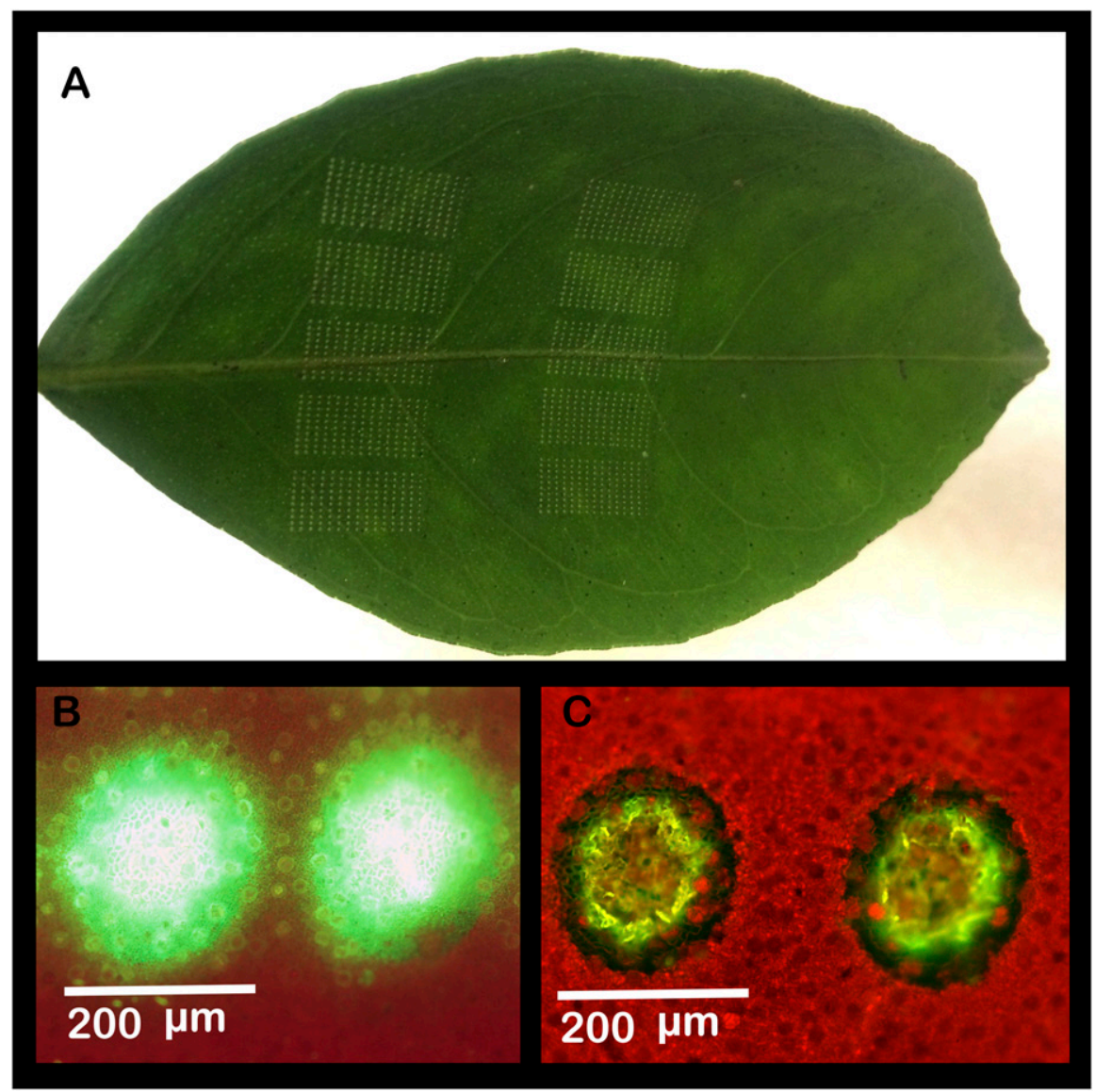

Fig. 1. Image of a citrus leaf (A) showing the pattern of wax dispersal created by laser light used to enhance penetration of nanoparticles. (B) Close-up of the wax cavities $2 \mathrm{~h}$ after application of fluorescent trehalose. (C) Close-up of control untreated wax cavities.

PAMAN dendrimer NPs were purchased from Sigma Chemical (St. Louis, MO) and $\mathrm{Q}$ trackers form Molecular Probes (Eugene, OR). Fluorescent probes (Alexa-488; Molecular Probes, Eugene, OR; and FITC, F7250; Sigma-Aldrich, St. Louis, MO) were attached to PAMAM dendrimers following the method of Chen et al. (2011). To prevent disturbing the original properties, NPs were used without dilution at the concentrations shown in Table 1.

Zeta potential of the NPs was measured using Brookhaven ZetaPlus in $10 \mathrm{~mm}$ $\mathrm{KCl}$ at $\mathrm{pH} 5.5$ using Smoluchowski's approximation.
Plant material and NP application. Twoyear-old 'Valencia' orange (Citrus sinensis L. Osbeck) trees on Swingle (Citrus paradisi $\times$ Poncirus trifoliata) rootstock grown in 4 -L pots were kept in a greenhouse with natural lighting. When needed for experimental treatment, trees were brought to the laboratory and treated accordingly. To ensure consistency, trees were made free of HLB and leaves were made free of other pests. From each tree, one fully expanded mature leaf was selected and thoroughly wiped off with distilled water to eliminate any pesticide residue used in the greenhouse.
To assist in the initial penetration of the NPs into the leaf tissue, we used a laser light beam which created superficial perforations in the cuticle (Fig. 1A) (Etxeberria et al., 2009) allowing the NPs to reach the cell wall space. Leaves were lasered using a lowenergy carbon dioxide laser etching machine (model XY Mark-10; GPD Technologies, Peachtree City, GA) located at the University of Florida's Citrus Research and Education Center in Lake Alfred, FL. Laser specifications used were those already reported for citrus fruits (Sood et al., 2009) and leaves (Etxeberria et al., 2016). We used the dot matrix pattern where the surface area of one dot was $\approx 3.14 \times 10^{-4} \mathrm{~cm}^{2}$, and the energy per surface area of one dot was $0.00785 \mathrm{~W} / \mathrm{dot} /$ $10^{6} \mathrm{~s}$. These energy levels had been predetermined from previous work (Etxeberria et al., 2016). Immediately after lasering, $7 \mu \mathrm{L}$ of NP solutions were manually smeared on each lasered area.

Assessment of NP penetration and movement. To maximize the ability to track the particles inside the leaf, and given that concentration was not a factor for our studies, commercially obtained NP solutions were used directly without dilution. Laboratory prepared NP were used at the maximum concentration possible anticipating a considerable reduction factor as NPs penetrate the leaf tissue. All NPs (Table 1) were fluorescent and their passage through the cell wall traced under fluorescence microscopy using a Carl Zeiss Axion Scope A-1 (Carl Zeiss Microscopy GmbH, Göttingen, Germany) equipped with a Canon EOS Rebel T3I camera (Cannon Inc., Tokyo, Japan).

\section{Results}

To validate the experimental design, an initial experiment using fluorescent trehalose (MW 744; Ex/Em 490/525) was carried out. Trehalose is a naturally occurring sugar in plants (Muller et al., 1997) and an analog of sucrose $(\approx 7 \AA)$, the most abundant saccharide in the plant kingdom (Pontis, 1977). A $14 \mu \mathrm{L}$ aliquot of $2.7 \mathrm{~mm}$ fluorescent trehalose (FITC-trehalose; EOX101, Kerafast, Boston, MA) solution was manually applied directly over the etched surface and immediately covered with a thin layer of natural oil. Oil was applied to prevent loss of water through the pores, a condition that could have resulted in desiccation, disrupting the natural flow of water through the leaf and affecting the movement of applied substances. Figure 1B shows the adaxial (upper) side of the leaf $2 \mathrm{~h}$ after treatment. Green fluorescence emanates from the etched surface depressions and surrounding tissue framed by the red autofluorescence of the underlining chlorophyll. In control etched but untreated leaves, only the ruptured cuticle shows fluorescence (Fig. 1C). Penetration and movement of trehalose through the cell wall space is demonstrated in Fig. 2A and $\mathrm{B}$ where fluorescence can be seen inside the leaf blade (Fig. 2A). After $4 \mathrm{~h}$, fluorescence marked the phloem tissue at the base of the petiole (Fig. 2C and D). The above data 
demonstrate that: 1) externally applied trehalose reached the cell wall space through the laser-generated pores; 2) applied trehalose solution was able to diffuse through the apoplastic milieu; and 3) trehalose reached the vascular tissue, was taken up by phloem cells, and transported down the leaf.

Green fluorescent gold NPs (Au-NPs) $1.4 \mathrm{~nm}$ in diameter (Alexa Fluor-488 nanogold; Nanoprobes, Yaphank, NY) were subsequently applied under the same conditions as described above. After $4 \mathrm{~h}$, Au-NPs had moved through the cell wall space as demonstrated by the green fluorescence in cross sections of leaf blades (Fig. 3A) compared with the control untreated leaves (Fig. 3B). The intense fluorescence inside the leaf is an indication that the particles traveled from the site of application to the leaf interior. Furthermore, when the corresponding leaf petioles were examined (several $\mathrm{mm}$ down from the point of application) after $4 \mathrm{~h}$, palpable NP fluorescence was visible within the phloem cells (Fig. 3C), a condition not present in unlasered leaves (same as Fig. 2D). Figure 3D, a closeup of the vascular tissue in Fig. 3C, unquestionably demonstrates that the fluorescence emanates from the phloem tissue. Application of $\mathrm{CuInS} / \mathrm{ZnS}$ nanocrystals (mKNANO, Mississauga, ON) $3.6 \mathrm{~nm}$ in diameter produced similar results (Fig. 4A and B). The particles entered the leaf blade (Fig. 4A) and moved down the petiole through the vascular system (Fig. 4B).

Leaves treated with fourth generation Alexa-488-conjugated PAMAM dendrimers $4.6 \mathrm{~nm}$ in diameter also displayed internal fluorescence, albeit with decreased intensity and longer treatment times. We were not able to detect significant movement of PAMAM fluorescent dendrimers within $4 \mathrm{~h}$ of application. However, their presence in the leaf tissue (Fig. 4C) and vasculature of the petiole (Fig. 4D) $24 \mathrm{~h}$ after application also denotes that 4.6-nm PAMAM dendrimers were able to move through the leaf cell wall and were taken up by sieve elements despite differing in composition from the 3.6-nm CuInS/ZnS nanocrystals and 1.4-nm Au-NPs above. These results not only demonstrated that the pore size of citrus leaf cell walls is of at least $4.5 \mathrm{~nm}$, but most importantly, that NPs were able to enter the phloem cells and subsequently moved down with the phloem current. In terms of relative fluorescence, direct comparisons with the smaller NPs cannot be made since these NPs are of different chemical composition and applied at different concentrations.

FITC-PAMAM NPs of $5.4 \mathrm{~nm}$ in diameter (G-5) also penetrated and moved through the cell wall, and were taken up by the phloem tissue (Fig. 5A and B). However, only a percentage of micrographs displayed fluorescence compared with leaves treated with smaller size NPs, indicating that these sized particles were reaching the size exclusion limit of the cell wall. No penetration of NPs took place when FITCPAMAM (G-6) NPs $6.7 \mathrm{~nm}$ in diameter (Fig. 5C and D) or when CdSe/ZnS Q-dots

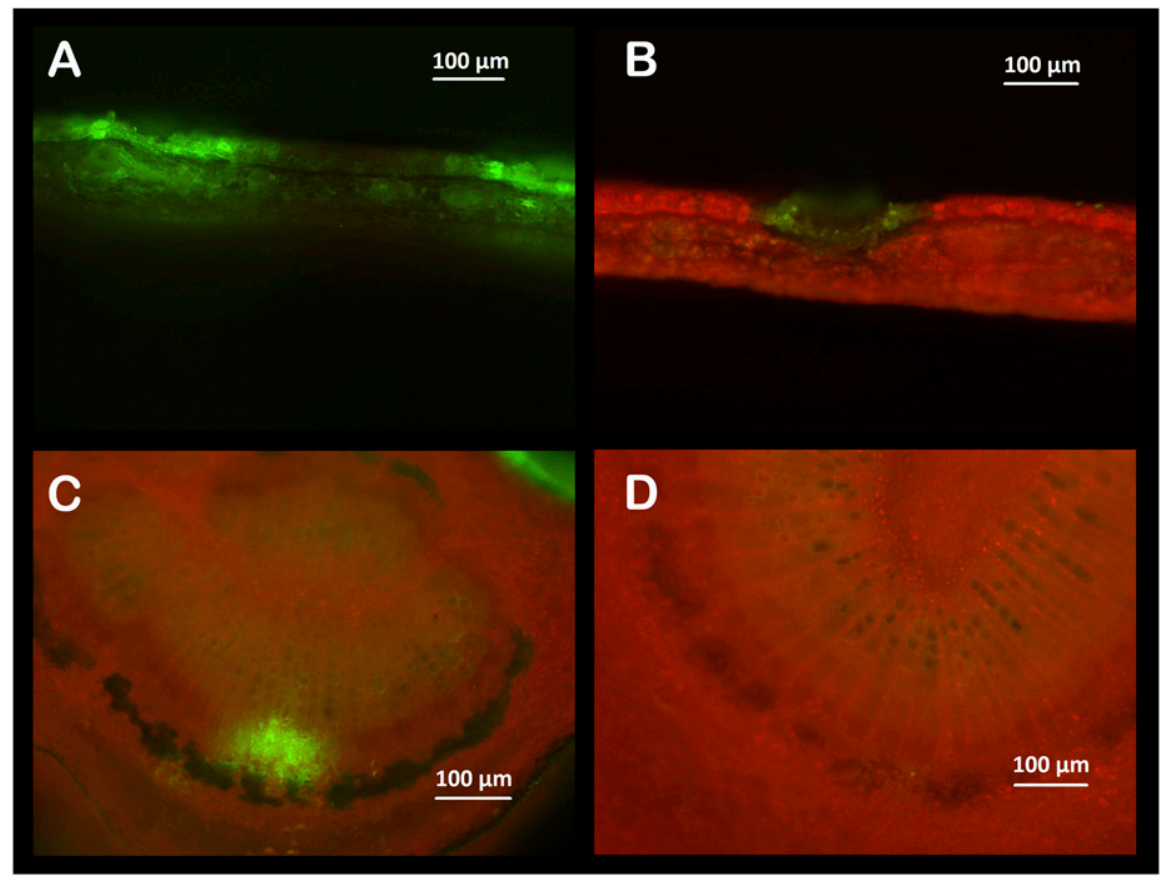

Fig. 2. Fluorescence micrographs of citrus leaves treated with fluorescent trehalose. Trehalose was applied on lasered areas to increase penetration through the cuticle. (A) Cross-section of a citrus leaf blade displaying extensive internal green fluorescence from trehalose $2 \mathrm{~h}$ after application. (B) Cross-section of a control untreated leaf. (C) Cross-section of a citrus leaf petiole $4 \mathrm{~h}$ after application of fluorescent trehalose on the lasered leaf blade. Observe fluorescence restricted to the phloem tissue. (D) Crosssection of a petiole from a control untreated leaf.

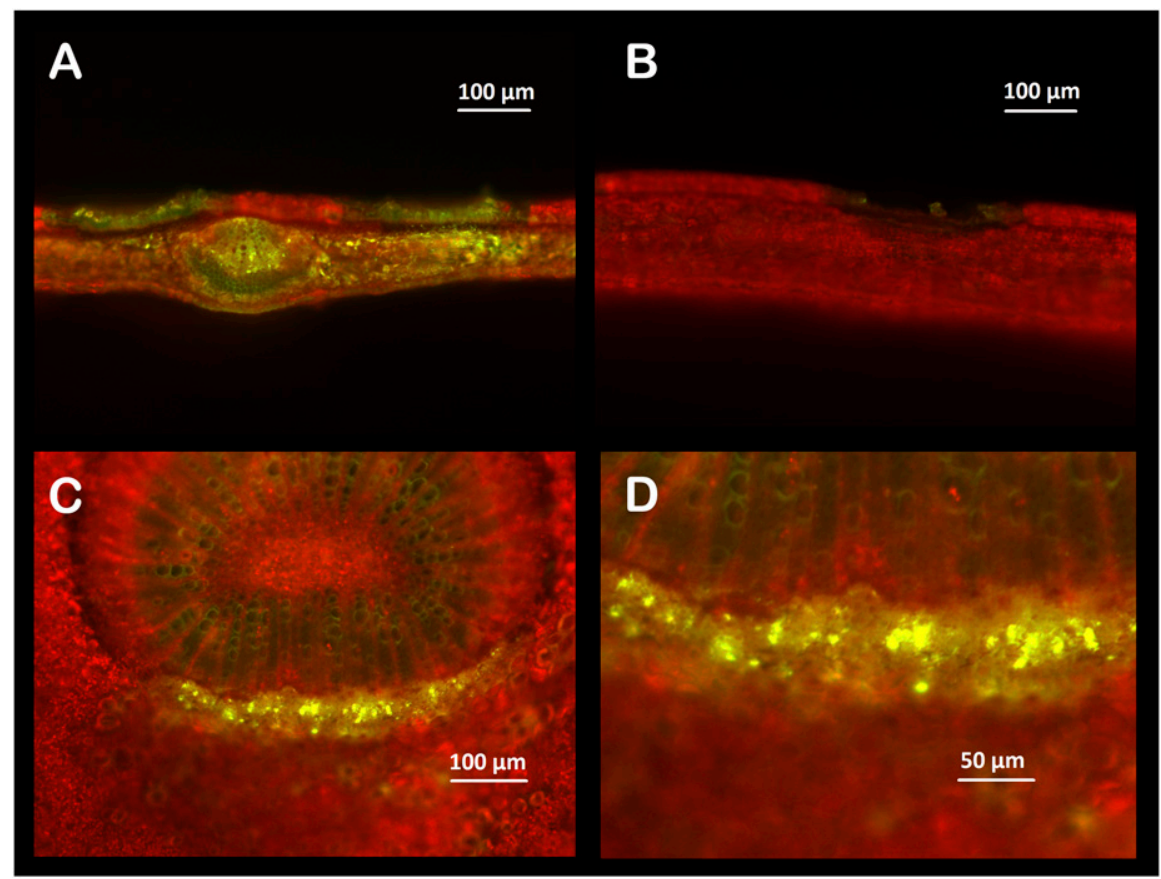

Fig. 3. Fluorescence micrographs of citrus leaves overlaid with fluorescent 1.6-nm Au-nanoparticles (NPs). Au-NPs were applied on lasered areas to improve penetration through the cuticle. (A) Crosssection of a citrus leaf blade displaying green fluorescence from Au-NPs $2 \mathrm{~h}$ after application. (B) Cross-section of a control untreated leaf. (C) Cross-section of a citrus leaf petiole $4 \mathrm{~h}$ after application of fluorescent Au-NPs. Note fluorescence emanating from the phloem tissue. (D) Enlarged view of the leaf petiole in $\mathbf{C}$.

of 10 and $15 \mathrm{~nm}$ in diameter were used (Fig. 6).

To determine whether the laser light used to perforate the cuticle had any effect on the structure of the cell wall that could have altered the cell wall pore size, we repeated the experiments by removing the epidermis with sand paper, as customarily 


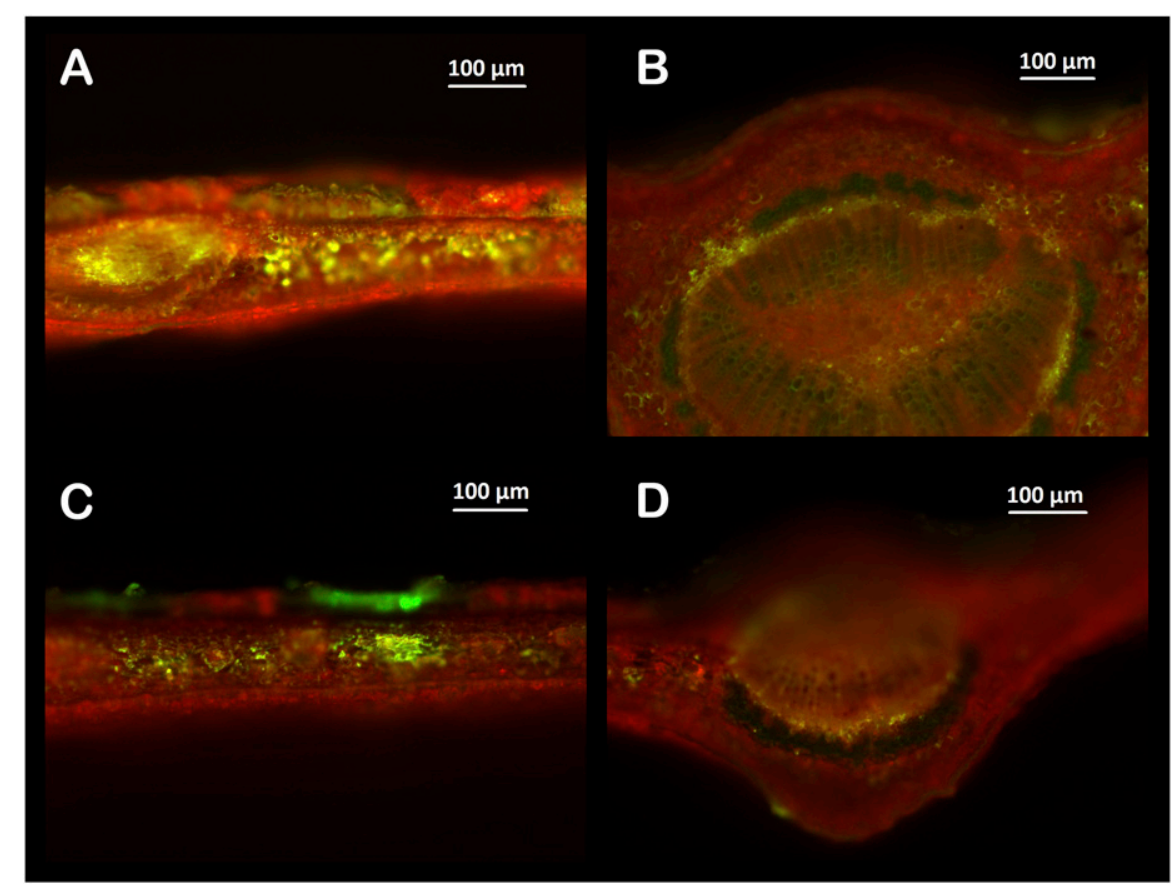

Fig. 4. Fluorescence micrographs of citrus leaves overlaid with fluorescent 3.6-nm CuInS/ZnS nanoparticles (A, B) and 4.6-nm Alexa-PAMAM (C, D) dendrimer NPs. The NPs were applied on lasered areas to improve penetration through the cuticle. (A) Cross-section of a citrus leaf blade displaying green fluorescence from $\mathrm{CuInS} / \mathrm{ZnS} 2 \mathrm{~h}$ after application. (B) Cross-section of the petiole $4 \mathrm{~h}$ after application. (C) Leaf blade $24 \mathrm{~h}$ after fluorescent PAMAM dendrimer application. (D) Cross-section of a citrus leaf petiole $24 \mathrm{~h}$ after application of fluorescent PAMAM dendrimer application. Phloem tissue is visibly fluorescent.

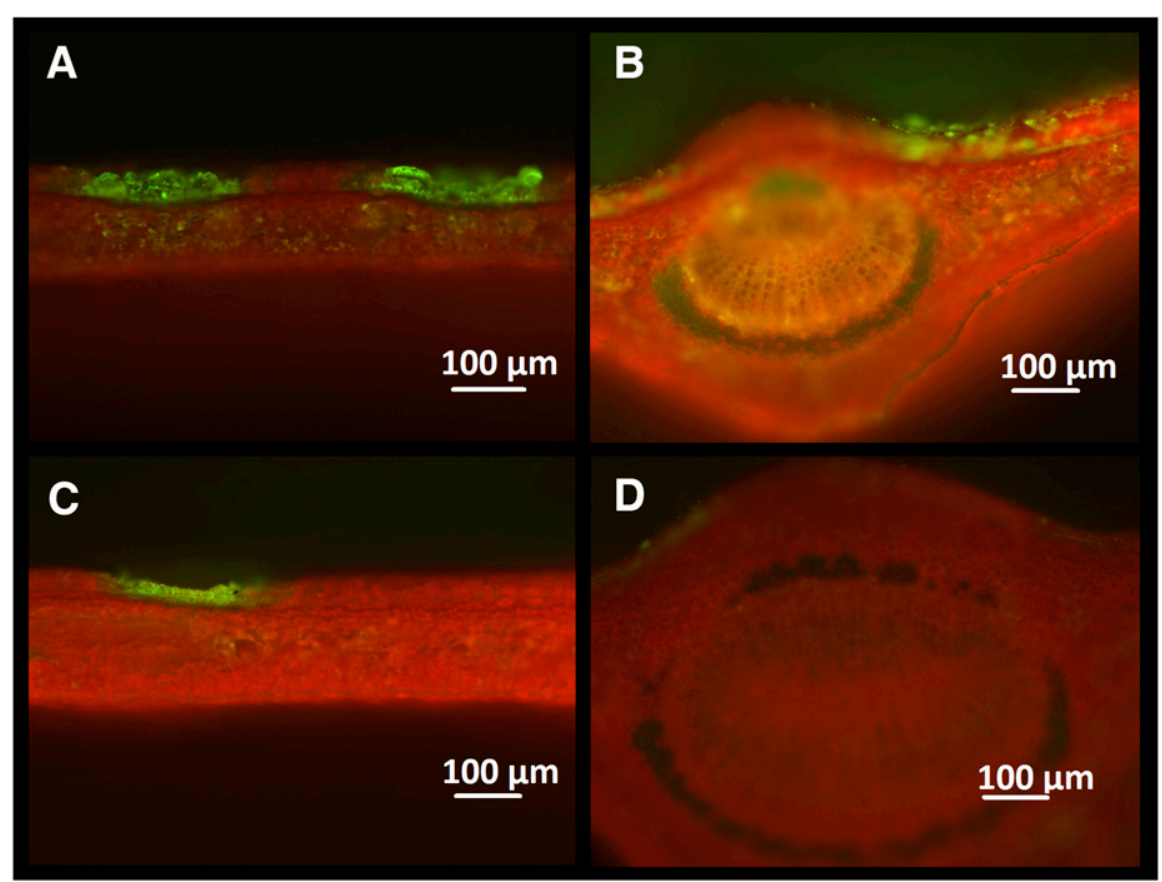

Fig. 5. Fluorescence micrographs of citrus leaves overlaid with FITC-PAMAM dendrimer of $5.4 \mathrm{~nm}$ in diameter (A, B) and FITC-PAMAM dendrimer of $6.7 \mathrm{~nm}$ in diameter $(\mathbf{C}, \mathbf{D})$. The nanoparticles were applied on lasered areas to improve penetration through the cuticle. (A) Cross-section of a citrus leaf blade displaying green fluorescence from FITC-PAMAM G-5 dendrimer $24 \mathrm{~h}$ after application. (B) Cross-section of the petiole $24 \mathrm{~h}$ after application. (C) Leaf blade $24 \mathrm{~h}$ after FITC-PAMAM G-6 dendrimer application. (D) Cross-section of a citrus leaf petiole $24 \mathrm{~h}$ after the application of FITCPAMAM G-6 dendrimer. The arrow indicates phloem tissue.

done in phloem loading experiments (Knoblauch et al., 2015). Other than the higher levels of NP penetration due to the larger leaf area exposed, movement of NPs from the application site was identical to those described above using laser light, corroborating that $5.4-6.7 \mathrm{~nm}$ is the size exclusion limit.

\section{Discussion}

The ability of NPs to penetrate live plant cell walls has direct implications in the future design of strategies involving NPs for agricultural purposes (Miralles et al., 2012). As opposed to animal cells, plant cell walls constitute a major obstacle in the implementation of nanotechnology in plant systems. A number of factors influence the penetration and movement of NPs in plant cells, of which size and water content constitute the most critical parameters (Paes, 2014). In the case of foliar application of NPs for agricultural purposes, size is critical not only for the dispersion through the leaf cuticle and stomata (Eichert et al., 2008), but also for their movement through the cell wall matrix. A substantial number of reports have documented the penetration of NPs into plants mostly through very young roots (Hischemöller et al., 2009; Kurepa et al., 2010; Zhu et al., 2008), tissue cultured cells (Kokina et al., 2013; Santos et al., 2010), stem parenchyma cells (Corredor et al., 2009), and protoplasts (Etxeberria et al., 2006). However, leaves, the most targeted tissue for agricultural practices (Zhang and Brown, 1999), have not been investigated.

Given that the NPs used in this study were of different concentrations and chemical configurations, we limited our study at discerning the upper size limit of the cell wall space and not their movement properties within the tissue, realizing these characteristics are influenced by many other factors (Dietz and Herth, 2011; Yang et al., 2013). In our experiments, we used laser light only as a means to facilitate entrance of NPs into the leaf tissue at levels that enable their internal tracking by fluorescence microscopy. Although NPs have been shown to enter plant leaves through stomata (Eichert et al., 2008), the process is highly inefficient (particles only detected after $2 \mathrm{~d}$ in high humidity in no more than $10 \%$ of stomata) to allow investigations on NP movement under the conditions used in this investigation.

Our data using fluorescent NPs of different sizes and chemical compositions indicate that the maximum cell wall pore size of citrus leaves is $\approx 5.4 \mathrm{~nm}$. This conclusion is based on the ability of FITC-PAMAM NPs $5.4 \mathrm{~nm}$ in diameter to travel though the leaf tissue (Fig. 5A and B), but the inability of FITCPAMAM NPs $6.7 \mathrm{~nm}$ in diameter to move from the point of application (Fig. 5C and D). Since both of these particles were of the same composition and charge, the lack of internal movement by the FITC-PAMAM NPs $6.7 \mathrm{~nm}$ in diameter must have been due to their size (Stokes radius). The fact that the free soluble forms of the fluorescent fluorophores Alexa488 and FITC were incapable of moving through the cell wall (Etxeberria et al., 2016) demonstrates that the fluorescence observed inside the leaf and within the phloem (Figs. 3-5) had to be from the NP-conjugated fluorophores (Alexa-488-PAMAM G-4 and FITC-PAMAM G-5) and not from free fluorescent dyes. These observations also substantiate 


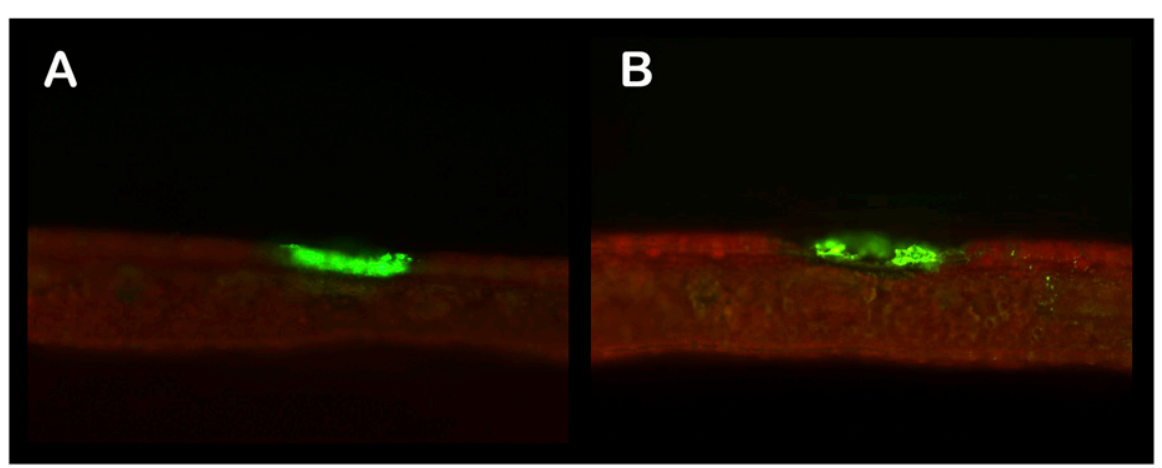

Fig. 6. Fluorescent micrographs of cross-sections of lasered citrus leaves supplied with $\mathrm{CdSe} / \mathrm{ZnS}$ nanodots of (A) $10 \mathrm{~nm}$ and (B) $15 \mathrm{~nm}$ in diameter. Leaves were observed $24 \mathrm{~h}$ after application.

the physical integrity of the G-4, G-5, and G-6 PAMAM NPs and validate our conclusions.

It should be noted that both condensed (Au-NPs, CuInS/ZnS nanocrystals) and soft (fourth to sixth generation PAMAM dendrimers) NPs were employed in the study, and these NPs possessed different surface charges $(-18.1 \mathrm{mV}$ for $\mathrm{Au}-\mathrm{NPs},-29.2 \mathrm{mV}$ for $\mathrm{CuInS} / \mathrm{ZnS}$ nanocrystals, and $+30.7,+23.2$, and $+5.35 \mathrm{mV}$ for cationic PAMAM dendrimers fourth, fifth, and sixth generation, respectively). Despite their different charges and consequential different affinities for the plant cell wall, all NPs $\leq 5.4 \mathrm{~nm}$ were able to move from the point of application through the cell wall until reaching the phloem tissue. For PAMAM dendrimers of the fourth and higher generations, their large numbers of branching and primary amine end groups significantly reduce their internal voids, rendering minimal fluctuations in their radii of gyration $(<2 \%)$ (Geitner et al., 2014) and structural flexibility to mimic that of condensed NPs. It should be pointed out that our observations were made in live potted plants grown under greenhouse conditions, circumstances that closely resembled the natural growing environment. It is likely that particles (other than those used in this study) with different surface charges may have different abilities to penetrate and move through the cell wall (Schwab et al., 2015). However, our studies focused on size limitations, a property we were able to define.

Although transport of NPs through the phloem had been indirectly implied by the transfer of NPs across two generations (Lin et al., 2009), our data constitute the first direct demonstration of NPs uptake by phloem cells and their transport down the vascular tissue. Since NPs can enter plant cells only by endocytosis (Etxeberria et al., 2005), our results demonstrate, for the first time, the process of endocytosis in phloem cells (companion cells and/or the enucleated sieve elements).

The implications from these studies are also significant in that they establish that NPs can be transported away from the site of application following the phloem flow and eventually delivered to heterotrophic cells likely through plasmodesmata $(\approx 40 \mathrm{~nm}$ in diameter) (Knoblauch and Oparka, 2012). In conclusion, our observations provide important insights and inroads into the challenges associated with the use of NPs for plant treatments. Aside from a maximum NP size, we report the transport of NPs away from the site of application in the phloem, fundamental for the development of a foliar system. Although the experiments presented here apply primarily to citrus, is likely that the size exclusion of other land plants may not vary significantly as predicted by the work of others using a variety of techniques (Albersheim et al., 2010; Carpita et al., 1979; Chesson et al., 1997; Fleischer et al., 1999; Woehlecke and Ehwald, 1995).

\section{Literature Cited}

Adani, F., G. Papa, A. Schievano, G. Cardinale, G. D'Imporzano, and F. Tambone. 2010. Nanoscale structure of the cell wall protecting cellulose from enzyme attack. Environ. Sci. Technol. 45:1107-1113.

Albersheim, P., A. Darvill, K. Roberts, R. Sederoff, and A. Staehelin. 2010. A. plant cell walls. Garland Science. ISBN 1136843582 , 9781136843587.

Arora, S., P. Sharme, S. Kumar, R. Nayan, P.K. Khanna, and M.G.H. Zaidi. 2012. Goldnanoparticle induced enhancement in growth and seed yield of Brassica juncea. Plant Growth Regulat. 66:303-310.

Carpita, N., D. Sabularse, D. Montesinos, and D.P. Delmer. 1979. Determination of the pore size of cell walls of living plant cells. Science 205:1144-1147.

Chen, P., Y. Yang, P. Bhattacharya, P. Wang, and P.C. Ke. 2011. A Tris-Dendrimer for hosting diverse chemical species. J. Phys. Chem. C 115:12789-12796.

Chesson, A., P.T. Gardner, and T.J. Wood. 1997. The cell wall porosity and available surface area of wheat straw and wheat grain fractions. J. Sci. Food Agr. 75:289-295.

Christou, P., D.E. McCabe, and W.F. Swain. 1988 Stable transformation of soybean callus by DNA-coated gold particles. Plant Physiol. 87:671-674.

Corredor, E., P.S. Testillano, J.M. Coronado, P. Gonzalez-Melendi, R. Fernandez Pacheco, C. Marquina, M.R. Ibarra, J.M. de la Fuente, D. Rubiales, A. Perez-de Luque, and M.C. Risueno. 2009. Nanoparticle penetration and transport in living pumpkin plants: In situ 9:45, doi: 10.1186/1471-2229-9-45. subcellular identification. BMC Plant Biol.
Cosgrove, D.J. 1997. Assembly and enlargement of the primary cell wall in plants. Annu. Rev. Cell Dev. Biol. 13:171-201.

Cosgrove, D.J. and M.C. Jarvis. 2012. Comparative structure and biomechanics of plant primary and secondary cell walls. Front. Plant Sci. 3:204, doi: 10.3389/fpls.2012.00204.

DeRosa, M.V.C., C. Monreal, M. Schnitzer, R. Walsh, and Y. Sultan. 2010. Nanotechnology in fertilizers. Nat. Nanotechnol. 5:91.

Dietz, K.J. and S. Herth. 2011. Plant nanotoxicity. Trends Plant Sci. 16:582-589.

Eichert, T., A. Kurtz, U. Steiner, and H.E Goldbach. 2008. Size exclusion limits and lateral heterogeneity of the stomatal foliar uptake pathway for aqueous solutes and water suspended nanoparticles. Physiol. Plant. 134:151-160.

Etxeberria, E., P. Gonzalez, E. Baroja-Fernandez, and J. Pozueta-Romero. 2006. Fluid phase uptake of artificial nano-spheres and fluorescent quantum-dots by sycamore cultured cells. Plant Signal. Behav. 1:196-200.

Etxeberria, E., P. Gonzalez, A. Fanton Borges, and C. Brodersen. 2016. The use of laser light to enhance the uptake of foliar-applied substances into citrus (Citrus sinensis) leaves. Appl. Plant Sci. 4:1500106, doi: 10.3732/apps.1500106.

Etxeberria, E., P.C. Gonzalez, P. Tomlinson, and J. Pozueta. 2005. Existence of two parallel mechanisms for glucose uptake in heterotrophic plant cells. J. Expt. Bot. 56:1905-1912.

Etxeberria, E., C. Narciso, P. Sood, P. Gonzalez, and J. Narciso. 2009. The anatomy of a laser label. Proc. Fla. State Hort. Soc. 122:347-349.

Fernandez, V. and T. Eichert. 2009. Uptake of hydrophilic solutes through plant leaves: Current state of knowledge and perspectives of foliar fertilization. Crit. Rev. Plant Sci. 28:3668.

Fleischer, A., M.A. O'Neill, and R. Ehwald. 1999. The pore size of non-graminaceous plant cell walls is rapidly decreased by borate ester crosslinking of the pectic polysaccharide rhamnogalacturonan. Plant Physiol. 121:829-838.

Geitner, N.K., B. Wang, R.E. Andorfer, D.A. Ladner, P.C. Ke, and F. Ding. 2014. Structurefunction relationship of PAMAM dendrimers as robust oil dispersants. Environ. Sci. Technol. 48:12868-12875.

González-Melendi, P., R. Fernández-Pacheco, J.M. Coronado, E. Corredor, P.S. Testillano, M.C Risueño, C. Marquina, M.R. Ibarra, D. Rubiales, and A. Pérez-de-Luque. 2008. Nanoparticles as smart treatment-delivery systems in plants: Assessment of different techniques of microscopy for their visualization in plant tissues. Ann. Bot. 101:187-195.

Gottwald, T.R. 2010. Current epidemiological understanding of citrus huanglongbing. Annu. Rev. Phytopathol. 48:119-139.

Hischemöller, A., J. Nordmann, P. Ptacek, K. Mummenhoff, and M. Haase. 2009. In-vivo imaging of the uptake of upconversion nanoparticles by plant roots. J. Biomed. Nanotechnol. 5:278-284

Jo, Y.K., B.H. Kim, and G. Jung. 2009. Antifungal activity of silver ions and nanoparticles on phytopathogenic fungi. Plant Dis. 93:10371043

Khodakovskaya, M., E. Dervishi, M. Mahmood, Y. Xu, Z. Li, F. Watanabe, and A.S. Biris. 2009. Carbon nanotubes are able to penetrate plant seed coat and dramatically affect seed germination and plant growth. ACS Nano 3:32213227. 
Knoblauch, M. and K. Oparka. 2012. The structure of the phloem-Still more questions than answers. Plant J. 70:147-156.

Knoblauch, M., M. Vendrell, E. Leau, A. Paterlini, K. Knox, T. Ross-Elliott, A. Reinders, S.A. Brockman, J. Ward, and K. Oparka. 2015. Multispectral phloem-mobile probes: Properties and applications. Plant Physiol. 167:12111220.

Kokina, I., V. Gerbreders, E. Sledevskis, and A. Bulanovs. 2013. Penetration of nanoparticles in flax (Lilium usitatissimum L.) calli and regenerates. J. Biotechnol. 165:127-132.

Kurepa, J., T. Paunesku, S. Vogt, H. Arora, B.M. Rabatic, J. Lu, M.B. Wanzer, G.E. Woloschak, and J.A. Smalle. 2010. Uptake and distribution of ultrasmall anatase $\mathrm{TiO}_{2}$ alizarin red S nanoconjugates in Arabidopsis thaliana. Nano Lett. 10:2296-2302.

Lamsal, K., S.W. Kim, J.H. Jung, Y.S. Kim, K.S. Kim, and Y.S. Lee. 2011. Application of silver nanoparticles for the control of Colletotrichum species in vitro and pepper anthracnose disease in field. Mycobiology 39:194-199.

Lara, H.H., E.N. Garza-Treviño, L. Ixtepan-Turrent, and D.K. Singh. 2011. Silver nanoparticles are broad-spectrum bactericidal and virucidal compounds. J. Nanobiotechnology 9:30-38.

Lin, S., J. Reppert, Q. Hu, J.-A.S. Hudson, M.L. Reid, T.A. Ratnikova, A.M. Rao, H. Luo, and P.C. Ke. 2009. Uptake, translocation, and transmission of carbon nanomaterials in rice plants. Small 5:1128-1132.

Liu, Q., B. Chen, Q. Wang, X. Shi, Z. Xiao, J. Lin, and X. Fang. 2009. Carbon nanotubules as molecular transporters for walled plant cells. Nano Lett. 9:1007-1010.

Martin-Ortigosa, S., J.S. Valenstein, V.S.Y. Lin, B.G. Trewyn, and K. Wang. 2012. Gold functionalized mesoporous silica nanoparticle mediated protein and DNA co-delivery to plant cells via the biolistic method. Adv. Funct. Mater. 22:3576-3582.

Miralles, P., T.L. Church, and A.T. Harris. 2012. Toxicity, uptake, and translocation of engineered nanomaterials in vascular plants. Environ. Sci. Technol. 46(17):9224-9239.
Mu, Q., D.L. Broughton, and B. Yan. 2009. Endosomal leakage and nuclear translocation of multiwalled carbon nanotubes: Developing a model for cell uptake. Nano Lett. 9:43704375.

Muller, J., T. Boller, and A. Wiemken. 1997. Trehalose and trehalase in plants: Recent developments. Plant Sci. 112:1-9.

Nair, R., S.H. Varghese, B.G. Nair, T. Maekawa, Y. Yishiba, and D. Sakthi Kumar. 2010. Nanoparticulate material delivery to plants. Plant Sci. 179:154-163.

Paes, G. 2014. Fluorescent probes for exploring plant cell wall deconstruction: A review. Molecules 19:9380-9402.

Panáček, A., M. Kolář, R. Verčeřová, R. Pricek, J. Soukupová, V. Kryštof, P. Hamal, R. Zbořil, and L. Kvítek. 2009. Antifungal activity of silver nanoparticles against Candida ssp. Biomaterials 30:6333-6340.

Pontis, H.G. 1977. The riddle of sucrose, p. 39. In: D.H. Northcote (ed.). International review of biochemistry, plant biochemistry II, vol. 13 . University Park Press, Baltimore, MD.

Powers, K.W., S.C. Brown, V.B. Krishna, S.C. Wasdo, B.M. Moudgil, and S.M. Roberts. 2006. Research strategies for safety evaluation of nanomaterials. Part VI. Characterization of nanoscale particles for toxicological evaluation. Toxicol. Sci. 90:296-303.

Prasad, R., V. Kumar, and K. Suranjit Prasad. 2014. Nanotechnology in sustainable agriculture: Present concerns and future aspects. Afr. J. Biotechnol. 13:705-713.

Rondeau-Mouro, C., D. Defer, E. Leboeuf, and M. Lahaye. 2008. Assessment of cell wall porosity in Arabidopsis thaliana by NMR spectroscopy. Intl. J. Biol. Macromol. 42:83-92.

Santos, A.R., A.S. Miguel, L. Tomaz, R. Malhoì, C. Maycock, M.C. Vaz Patto, P. Fevereiro, and A. Oliva. 2010. The impact of CdSe/ZnS quantum dots in cells of Medicago sativa in suspension culture. J. Nanobiotechnology 8:24.

Schwab, F., G. Zhai, M. Kern, A. Turner, J.L. Schnoor, and M. Weisner. 2015. Barriers, pathways and processes for uptake, translocation and accumulation of nanomaterials in plantsCritical review. Nanotoxicology 10:257-278.

Serag, M.F., N. Kaji, C. Gaillard, Y. Okamoto, K. Terasaka, M. Jabasini, M. Mokeshi, H. Mizukami, A. Bianco, and Y. Baba. 2011. Trafficking and subcellular localization of multi-walled carbon nanotubes in plant cells. ACS Nano 5:493-499.

Sood, P., C. Ference, J. Narciso, and E. Etxeberria. 2009. Laser etching: A novel technology to label Florida grapefruit. HortTechnology 19:504 510.

Tepfer, M. and I.E. Taylor. 1981. The permeability of plant cell walls as measured by gel filtration chromatography. Science 213:761-763.

Thul, S.T., K.S. Bijay, K. Sarangi, and R.A. Pandey. 2013. Nanotechnology in agroecosystem: Implications on plant productivity and its soil environment. Expert Opinion Environ. Biol. 2:1-7.

Torney, F., B.G. Trewyn, V.S. Lin, and K. Wang. 2007. Mesoporous silica nanoparticles deliver DNA and chemicals into plants. Nat. Nanotechnol. 2:295-300

Wang, Z., X. Xie, J. Zhao, X. Liu, W. Feng, J.C. White, and B. Xing. 2012. Xylem and phloembased transport of $\mathrm{CuO}$ nanoparticles in maize (Zea mays L.). Environ. Sci. Technol. 46:4434 4441.

Woehlecke, H. and R. Ehwald. 1995. Characterization of size permeation limits of cell walls and porous separation materials by highperformance size-exclusion chromatography. J. Chromatography 708:263-271.

Yang, D., J.M. Moran-Mirabal, J.Y. Parlenge, and L.P. Walker. 2013. Investigations of the porous structure of cellulosic substrates through confocal laser scanning microscopy. Biotechnol. Bioeng. 110:2836-2845.

Zhang, Q.L. and P.H. Brown. 1999. Distribution and transport of foliar applied zinc in pistachio. J. Amer. Soc. Hort. Sci. 124:433-436.

Zhu, H., J. Han, J.Q. Xiao, and Y. Jin. 2008. Uptake, translocation and accumulation of manufactures iron oxide nanoparticles by pumpkin plants. J. Environ. Monit. 10:713717. 